Ross, E, Derouin,A, Halstater, B, Covington, K, Kaprielian, V, Murphy, G, Dieter,P

\title{
Can We Learn in the Sandbox Together? \\ Interprofessional Case Conferences as Facilitation Tools
}

Short Title: Can We Learn in the Sandbox Together?

\author{
Elizabeth Ross, PT, DPT, MMSc \\ Duke University, Durham, NC \\ DUMC Box 104002, Durham, NC 27710 \\ elizabeth.ross@dm.duke.edu (919)668-5537 (Phone) (919)684-1846 (FAX) \\ Anne Derouin, DNP, CPNP \\ Brian Halstater, MD \\ Kyle Covington, PT, DPT, NCS \\ Victoria S. Kaprielian, MD \\ Gwendolyn Murphy, PhD \\ Patricia Dieter, MPA, PA-C
}


Ross,E, Derouin,A, Halstater,B, Covington, K, Kaprielian, V, Murphy, G, Dieter,P

\section{Notes on Contributors}

\section{Elizabeth Ross, PT, DPT, MMSc}

Dr. Ross is an Assistant Consulting Professor in the Doctor of Physical Therapy Division, Department of Community and Family Medicine, Duke University, Durham, NC.

\section{Anne Derouin, DNP, CPNP}

Dr. Derouin is an Assistant Professor in the Duke University School of Nursing and in the Department of Community and Family Medicine, Duke University, Durham, NC.

\section{Brian Halstater, MD}

Dr. Halstater is an Assistant Professor in the Division of Family Medicine, Department of Community and Family Medicine, Duke University, Durham, NC. He also serves as the Family Medicine Residency Program Director.

\section{Kyle Covington, PT, DPT, NCS}

Dr. Covington is an Assistant Professor in the Doctor of Physical Therapy Division, Department of Community and Family Medicine, Duke University, Durham, NC.

\section{Victoria S. Kaprielian, MD}

Dr. Kaprielian is Professor and Associate Dean for Faculty Development and Medical Education, Campbell University School of Osteopathic Medicine, Buies Creek, NC.

\section{Gwendolyn Murphy, PhD}

Dr. Murphy is an Assistant Consulting Professor in the Division of Community Health, Community and Family Medicine, School of Medicine, Duke University Durham, NC.

\section{Patricia Dieter, MPA, PA-C}

Ms. Dieter is Chief of the PA Division and Professor of Community and Family Medicine, Duke University, Durham, NC. 
Ross,E, Derouin,A, Halstater,B, Covington, K, Kaprielian, V, Murphy, G, Dieter,P

\title{
Can We Learn in the Sandbox Together? Interprofessional Case Conferences as Facilitation Tools
}

\begin{abstract}
Duke Medicine utilized interprofessional case conferences (ICCs) from 2008-2012 with the objective of modeling and facilitating development of teamwork skills among diverse health profession students, including physical therapy, physician assistant, medical doctor and nursing. The purpose of this publication was to describe the operational process used to develop and implement the ICCS and measure the success of the ICCs in order to shape future work. The ICCs were offered to develop skills and attitudes essential for participation in healthcare teams. Students were facilitated by faculty of different professions to conduct a comprehensive historical assessment of a standardized patient (SP), determine pertinent physical and lab assessments to undertake, and develop and share a comprehensive management plan. Cases included patient problems that were authentic and relevant to each professional student in attendance. The main barriers to implementation are outlined and the focus on the process of working together is highlighted. Evaluation showed high satisfaction rates among participants and the outcomes from these experiences are presented. The limitations of these results are discussed and recommendations for future assessment are emphasized. The ICCS demonstrated that students will come together voluntarily to learn in teams, even at a research-focused institution, and express benefit from the collaborative exercise.
\end{abstract}


Ross, E, Derouin,A, Halstater,B, Covington, K, Kaprielian, V, Murphy, G, Dieter,P

\section{Introduction}

Duke Medicine is heavily invested in research in addition to providing cutting-edge patient care and health professions education. At Duke, individual achievement has long been encouraged; teamwork is a relatively newer element in the education curricula. Research has shown that effective interprofessional healthcare delivery teams improve patient safety, patient and provider satisfaction, and health-system efficiency ${ }^{1}$ Additionally, research has shown that interprofessional simulation scenarios result in increased awareness of expertise in other professionals and understanding of the collaborative potential in working together, which matched the purposes of our efforts. ${ }^{2}$ With this objective of promoting effective teamwork among our future clinicians, we developed evidence-based interprofessional case conferences (ICCS) utilizing standardized patients (SPs) and measured student responses to them.

The ICCs were provided for Duke's Doctor of Physical Therapy (DPT), Masters of Science in Nursing (MSN), Accelerated Bachelor of Science in Nursing (ABSN), Physician Assistant (PA) and Medical Doctor (MD) students, as well as other health profession students from neighboring institutions, as an opportunity to collaborate on a patient-centered care management team. Jointly facilitated by volunteer Duke residents and faculty from the professional schools, the ICCs also role-modeled effective teamwork for the student participants. The ICCs were offered on the Duke campus during early evening hours, to allow broader participation of both facilitators and participants. 


\section{Accreditation information}

ICC learning experiences directly address national curriculum guidelines for interprofessional collaboration outlined and adopted by all health profession education programs. There is clear support for interprofessional work preparation in the accreditation standards for each of the professional schools represented in our ICCs.

Both the Institute of Medicine (IOM) and the American Association of Colleges of Nursing (AACN) recommend the provision of interprofessional education opportunities for healthcare professionals that enable providers of various disciplines to enter the workplace with confidence in their ability to interact with one another. The baseline communication skills improve the professional practice collaborative environment and are associated with improved patient safety and quality of care. ${ }^{3,4}$

The IOM challenges health professions educators to ensure students are armed with an ability to deliver patient-centered care as members of collaborative interprofessional teams. The guiding document for undergraduate nursing curriculum, entitled The Essentials of

Baccalaureate Education for Professional Nursing Practice, also recommends interprofessional communication and collaboration efforts to improve patient health outcomes. ${ }^{5,6}$ This recommendation is based on evidence that shows effective collaboration and interprofessional communication is imperative to patient safety and ensures efficient, cost-effective patientcentered care. ${ }^{3}$ Collaborative learning exercises help promote trust and respect among the team members and establish communication strategies which, carried forward, will ensure patient safety and quality of care. 
The Liaison Committee on Medical Education (LCME) proposed a new accreditation standard, ED-19-A, at its meeting in October 2012. The language of the new standard, which became effective July 1, 2013, reads: "The core curriculum of a medical education program must prepare medical students to function collaboratively on health care teams that include health professionals from other disciplines as they provide coordinated services to patients. These curricular experiences include practitioners and/or students from other health professions." 7

The Accreditation Review Commission on Education for the Physician Assistant (ARC-PA) includes standard B1.08 in its requirements for PA programs: "The curriculum must include instruction to prepare students to work collaboratively in interprofessional patient centered teams." $^{8}$ The Commission on Accreditation of Physical Therapy Education (CAPTE) includes standard CC-5.55: "Provide culturally competent care to patients/clients in tertiary care settings in collaboration with other practitioners;" and standard CC-5.17: [Graduates must] "Expressively and receptively communicate in a culturally competent manner with patients/clients, family members, caregivers, practitioners, interdisciplinary team members, consumers, payers, and policymakers." ${ }^{9}$

The goal of our innovative interprofessional collaborative experiences was in keeping with the accreditation standards for each of the professions: not necessarily to solve clinical cases, but to equip future clinicians with a clear understanding of the unique role each team member plays in the provision of healthcare, and to allow them to participate in flexible decision-making processes, optimizing the opportunity to develop fundamental communication skills. 
Ross, E, Derouin,A, Halstater,B, Covington, K, Kaprielian, V, Murphy, G, Dieter,P

\section{History of team training}

Team training began in the 1970s and has increased in importance since then as additional research demonstrates the value of interprofessional teams in healthcare. ${ }^{10}$ There has been a call in the literature for specifics on when and how to educate for the best outcome for interprofessional effectiveness in practice. Many institutions have developed training programs that include small to large numbers of students from a wide array of professional health disciplines. As evidence that effective interprofessional teams provide improved patient outcomes has mounted, more programs have been developed. ${ }^{10}$ Many different configurations of trainees and methods have been used, including case studies, various types of high- and lowfidelity simulation and voluntary interprofessional clinical experiences. The varied participant group sizes worked on an array of simple to complex cases which have been described in the literature. ${ }^{11-17}$ Measurement of the effects of these trainings has been sparse and difficult to capture in terms of clinical outcomes, but there have been attitude differences shown in the literature. $^{11,12}$

\section{Methods}

\section{Overview}

Duke's ICCs were extracurricular, evening interprofessional group experiences that gave students opportunities to collaborate on evaluation and development of a plan of care for a SP, for the purpose of experiencing working together as a team. After pilot testing the ICCs twice in 2006, we agreed to hold them quarterly. Following poor attendance at spring events, we reduced the yearly number to three. The dates for the subsequent ICCs were determined for 
the coming year by working around student schedules, as well as academic calendars of the professional schools and the varsity men's basketball schedule. The ICC planning committee, which included faculty from the four health professions programs plus additional professionals such as a psychologist and a dietician, met every month to develop the cases and plan for each conference location and implementation. Cases were developed using a specific process to include data for a complete history, review of systems, and physical exam. (Table 1) Careful consideration of the details of each case made the situations authentic and relevant to each student in attendance. None of the ICCS cases was repeated within a four-year sequence, to ensure that no student experienced the same case more than once. (Table 2) Locations for the ICCs were rotated to the participating academic settings to facilitate students' learning about the environments of the other professional programs. Recruitment of facilitators and training of the SPs were done during the month prior to each ICC.

Publicity for the ICCs, via email, in-class notifications and posters, including sign-up information, was sent to students one month prior to each ICC. The students were encouraged to register early because of limited capacity and to assist with planning. Students in pharmacology, nutrition, and social work from other nearby academic institutions were also invited to attend. Participation in the ICCs was voluntary and there was no fee. Registration was capped at 80, allowing for cancellations, to ideally obtain between 40 and 60 participants for each program.

The overarching educational goals for all ICCS were for students to understand and appreciate the value of interprofessional teamwork in clinical problem solving (history-taking, treatment planning and patient education) and to develop interprofessional communication skills. 


\section{Program sequence}

Each two-hour program started with a simple dinner. The students, who were pre-assigned to groups of six to eight with as much professional diversity as possible, ate together prior to the ICC as a group icebreaker. Each group was assigned two facilitators: faculty from the professional education programs and Family Medicine and Occupational Medicine residents who were interested in serving in an educational role. A Facilitator's Guide, which included a precise schedule and a debriefing of the ICC case, based on the format previously published on MedEd Portal, was provided for each facilitator at the orientation during the pre-ICC meal

(Appendix 1). ${ }^{18}$ Facilitators were explicitly told during orientation to emphasize that students were not being evaluated in any way; the goal was to work as a team and communicate effectively with other professions. In addition, the facilitators were told to emphasize safety and confidentiality in the session.

After the meal, faculty introduced participants and provided a brief overview of the case. Students were encouraged to develop a list of all the information they wanted to gather from an interview with the patient prior to the SP entering the room. Once the SP joined the group, three or four students sequentially interviewed the patient with the option to "time out" and consult with their professional colleagues in the group. After the interview, the SP was briefly excused from the room. The participant group discussed the information gleaned from the interview. The facilitators, in response to students' requests, provided related information about the SP's physical examination and laboratory findings. Students used all of the information to decide the SP's priority needs and develop an intervention plan. After the SP 
Ross, E, Derouin,A, Halstater,B, Covington, K, Kaprielian, V, Murphy, G, Dieter,P

was invited back into the room, other students counseled the SP, to discuss the plan of care and provide patient education. Upon completion of this session, the SP was excused and students reflected on the entire exercise, discussing take home points they would use in the future. Each ICC concluded by gathering all of the small groups together and briefly reflecting on the experience with a course facilitator. Key take home points identified by the students were highlighted and pertinent research and resources that would provide further learning from the case were offered.

With the exception of the initial ICC, students completed evaluation surveys developed by the ICC planning committee at the conclusion of the small-group discussion (Appendix 2). Because the primary purpose of the evaluation instrument was to assess student satisfaction and obtain feedback for program improvement, the survey was very brief and open-ended. The evaluation forms also served as drawing cards for token door prizes which served as incentives to complete evaluations and stay until the end of the conference.

Following each ICC event, the committee reviewed the evaluation results utilizing the information from the reviews to make changes in the program and create new cases.

\section{Results}

Over a five-year period (2008-2012), 17 ICC events were held. Thirteen unique patient cases were used, representing a diversity of primary diagnoses. A total of 642 students participated in the 17 ICCs with an average attendance of 37.8 (Min=16, Max=64). Within these 17 experiences, students could participate as many, or as few, times as they wished. Data was not collected that reflects the number of repeating participants. Average attendance was $70.9 \%$ of 
those who had registered. Average percent attendance for the four professional student groups was: Nursing (16.6\%), DPT (22.7\%), PA (37.1\%), and MD (23.6\%). Occasionally other professional students were represented, based on their availability. On three occasions PharmD students participated and average attendance for the PharmD students for those three ICCs was 2.67 participants. Once each, dietitian $(n=5)$ and social work $(n=7)$ students participated. There was no relationship found between attendance of any given profession and the physical location of the ICC.

Faculty facilitators representing each of the four professions worked with all 17 ICCs. In addition, PhD trained faculty were involved in most of the ICCs. On four occasions pharmacy faculty were also present. The average faculty attendance was 10.1 with a range of 8-13.

A total of 536 respondents completed evaluation surveys across the 16 ICC events from which this data was collected, representing an $83.49 \%$ response rate of the full participant pool. Combined data from the 16 ICC events revealed high levels of satisfaction among the participating students; (Table 3) 30.2\% of the respondents indicated being "satisfied" and $68.1 \%$ of respondents indicated feeling "very satisfied" with the experience. Representative responses from the open-ended questions are included in Table 4.

\section{Discussion}

Our evaluation survey results indicate that the ICCs were influential in promoting teamwork among health professions students at Duke University. Without the pressure of being evaluated while working with a SP in a simulation setting, students were provided the opportunity to learn interviewing techniques, recognize the unique perspective of each 
professional team member, and build communication skills which will enhance their future professional practice. Participants viewed the experience as enjoyable, engaging, and effective in building relationships with colleagues in other professions. Our results reflect similar findings

to other studies that have assessed student attitudes after an interprofessional experience. ${ }^{11-13}$ Hall and Weaver express a need for "a clear and recognizable idea must serve as the focus for teamwork" which our experience using a specific patient scenario provides. ${ }^{15}$

Students appreciated the opportunity to collaborate with peers and faculty members of other healthcare disciplines and sought opportunities following the ICCs to utilize their skills in clinical environments. Enthusiastic word-of-mouth from many ICC participants spurred requests for additional events and collaborative learning opportunities from nursing and physical therapy students. The positive response was also evidenced by collaborations and partnerships among health professions students in learning experiences outside of ICC's. Many participants forged relationships in community research and collaborative provision of clinical care at Duke Health System following the ICCs. Examples of the collaborations included the development of teambased case simulation experiences among the medical and nursing students, and a proposed "learner clinic" which would model interprofessional provision of care among the medical, nursing and PA schools. Professional relationships between health professions students were initiated at the ICCs, which transferred to the clinical environments as the participants recognized one another from the experience, having already developed mutual trust. Additionally, mutual respect of the various interviewing skills, priorities of care and communication styles modeled by the ICC facilitators served to foster these traits in the professional school students as they progressed and matured in practice. 
While our results seem to indicate positive outcomes from the ICCs it must be noted that all participation was voluntary, meaning that those who participated were predisposed to value this opportunity. This is a clear limitation of the data presented here. There has been ongoing discussion among the professional schools to enlarge this model to a required ICC experience at least once during each health professional student's education. Comparison of responses from an unselected population will be valuable in further assessing this educational strategy.

Another consideration of our results is that the data does not measure individual participant acquisition of skills or observable behaviors that indicate change from this experience. Rather, our data is qualitative and reflects student attitudes and responses to this experience, which may be valuable in the ultimate development of these professionals as team players in the medical environment of the future. Further, we have not measured outcomes and we do not know how these results will translate into clinical practice. These considerations should guide future research efforts.

The ICC planning committee also benefitted from this educational approach, not only by developing well-planned patient scenarios, which can be revised and reused in future sessions, but also by building positive collaborations among faculty of the various professional schools. These collaborations led to further innovative educational, clinical or research opportunities. An example of the outgrowth of ICCS at Duke Medicine is a collaborative interprofessional prevention course on population health promotion and disease prevention, which has substantially enlarged the cohort of faculty actively committed to interprofessional implementation. Offered annually, the one-credit, on-campus course features team-based 
Ross, E, Derouin,A, Halstater,B, Covington, K, Kaprielian, V, Murphy, G, Dieter,P

learning activities designed for interprofessional groups from each of the 4 health professions programs at Duke. Faculty members who met initially for the development and implementation of the ICCs are currently participating in funded interprofessional research, consulting each other for expertise in the classroom, and presenting workshops together related to this content.

We learned several things that helped make ICCs and future case development more efficient. First, unless there was an important reason to select a specific age/gender/race, it was best to make cases gender neutral and provide a range of ages to allow for a wide variety of actors to assume the role at each ICC. Second, it was critical that facilitators attended the orientation and reviewed the faculty guide prior to the learning session with students, enabling them to readily provide pertinent patient information during their ICC session. Finally, each case study had to be relatively uncomplicated as a patient problem, yet include intervention opportunities for all of the professional students in attendance.

The benefits of interprofessional learning exercises are invaluable for the students, but planning for the events can be challenging, especially in a busy multidisciplinary academic setting. Our experience over the past five years provided us with insights into the challenges that were not initially foreseen by the planning committee. Critical considerations included scheduling, location of the ICC event, establishing a faculty champion from each of the participant schools to encourage student and facilitator attendance, administrative support and funding.

Scheduling the event far ahead was critical to success, as was the timing of the event. At Duke, we learned after one ICC was scheduled prior to mid-term exams, and another on the eve of a 
rival basketball game, that planning around all academic calendars (each school had a slightly varied schedule) as well as the athletics and arts calendars was required to avoid poor participant turn-out. Early evening proved to be an effective meeting time, as it avoided the complexities of matching class schedules across programs. Providing a light meal for participants and facilitators gave an additional incentive for participation.

An accommodating location is also critical to the success of ICCs. Adequate meeting spaces, with a private room available for each of the small groups to interview a patient, as well as a large-group meeting space for the closing discussion, are important. This can be a challenge to arrange on a crowded academic campus. Rotating the location among the various schools provided an opportunity for students to gain appreciation of the environment within each professional school and expand their Duke experience outside of the silo of their own academic setting. The challenge, however, was reserving enough space at each school and communicating the needs for the event to the respective administrators. It was also important to ensure that participants knew the physical location of the meeting place, provided by a map with their reminder notification.

It is crucial for ICCs collaborative design to have a designated champion at each of the schools. This requires the identification of a key faculty member at each professional school who is willing and able to publicize the date, location and learning objectives to their peers and students. An eager participant in the planning and facilitation of the ICC's, each professional school "champion" is naturally the role model for the students who actively encourages student participation and enthusiastically promotes the value of the ICC experience. 
Ross, E, Derouin,A, Halstater, B, Covington, K, Kaprielian, V, Murphy, G, Dieter,P

Additionally, it is essential that there be an administrative staff person with dedicated time for publicizing the ICCs, enrolling students, recruiting facilitators, arranging the meals and space, preparing the documents for ICCs, scheduling the committee meetings and overseeing the entire implementation process. Finally, funding is necessary for the meals, the SPs, the document preparation, as well as, the space, possibly, and faculty work effort.

\section{Conclusion}

Our experiences in developing and implementing Interprofessional Case Conferences with MD, PA, DPT and ABSN students provided excellent opportunities for faculty and students to engage in interprofessional collaboration. The process of development of the ICCs, which proved to be genuinely enjoyable and engaging, reflected the collaborative work we sought to encourage in our students. The benefits of these early experiences in our students' education could ultimately provide more confidence and effectiveness in their practices, as well as more complete and holistic care for their patients. While our purpose in this publication was to share the process we used to provide ICCs to students at Duke University and measure their responses to it, we have also identified the future work that needs to be done to measure the effects of these experiences on the translation of attitudes derived from the ICCs into clinical practice. 
Ross, E, Derouin,A, Halstater,B, Covington, K, Kaprielian, V, Murphy, G, Dieter,P

\section{Acknowledgments}

The authors wish to express sincerest gratitude to Randa McNamara, Director of the Clinical Skills Laboratory at Duke University, and the Standardized Patients she diligently and professionally trained for participation in all of the Interprofessional Case Conferences.

Additionally, enthusiastic thanks are extended to Kate Holeman for her tireless administration, management and documentation necessary to the successful implementation of the Interprofessional Case Conferences.

\section{Funding/Support}

The ICCs were supported by Undergraduate Medical Education in the School of Medicine, the Department of Community and Family Medicine, the School of Nursing, the Doctor of Physical Therapy and the Physician Assistant programs. Donations for door prizes were provided by individual contributions from facilitators and the University Bookstore at Duke University. 


\section{References}

1. Baker DP, Salas E, King H, Battles J, Barach P. The Role of Teamwork in the Professional Education of Physicians: Current Status and Assessment Recommendations. Joint Commission Journal on Quality and Patient Safety. 2005 April 2005;31(4):185-202

2. King $A E$, Conrad $M$, Ahmed RA. Improving collaboration among medical, nursing and respiratory therapy students through interprofessional simulation. Journal of interprofessional care. 2013 May;27(3):269-71.

3. Lakhani J, Benzies K, Hayden KA. Attributes of interdisciplinary research teams: a comprehensive review of the literature. Clin Invest Med. 2012;35(5):E226.

4. Greiner A, Knebel E, Institute of Medicine (U.S.). Health Professions Education: A Bridge to Quality. Washington, DC: National Academy of Sciences; 2003. Available from: http://www.iom.edu/Reports/2003/health-professions-education-a-bridge-to-quality.aspx.

5. Hirokawa RY, Daub K, Lovell E, Smith S, Davis A, Beck C. Using a human patient simulator to study the relationship between communication and nursing students' team performance. J Nurs Educ. 2012 Nov;51(11):647-51.

6. American Association of Colleges of Nursing. Essentials of Baccalaureate Education for Professional Nursing Practice2008.

7. The Liaison Committee on Medical Education. Proposed New Accreditation Standard ED19-A. 2012 [4/25/2013]; Available from: http://www.lcme.org/start.htm.

8. Accreditation Commission on Education for the Physician Assistant (ARC-PA). Accreditation Standards for Physician Assistant Education. [updated 7/2010, 10/2011; cited 2013 May 2 
Ross, E, Derouin,A, Halstater,B, Covington, K, Kaprielian, V, Murphy, G, Dieter,P

2013]; Fourth Edition:[Available from: $\underline{\text { http://arc- }}$

pa.org/documents/Standards4theditionwithclarifyignchanges10.2011fnl.pdf.

9. CAPTE(Commission on Accreditation in Physical Therapy Education) Handbook, [updated January 2013]. Available from:

http://www.capteonline.org/uploadedFiles/CAPTEorg/About CAPTE/Resources/Accreditat ion Handbook/EvaluativeCriteria PT.pdf

10. Interprofessional Education Collaborative Expert Panel. Core Competencies for Interprofessional Collaborative Practice: Report of an Expert Panel.: DC: Interprofessional Education Collaborative; 2012 [updated 2011March 21, 2013]; Available from: http://www.aacn.nche.edu/education-resources/ipecreport.pdf.

11. Eccott L, Greig A, Hall W, Lee M, Newton C, Wood V. Evaluating Students' Perceptions of an Interprofessional Problem-Based Pilot Learning Project. Journal of Allied Health. Winter 2012; 41(4):185-189.

12. King AE, Conrad M, Ahmed RA. Improving Collaboration Among Medical, Nursing and Respiratory Therapy Students through Interprofessional Simulation. Journal of Interprofessional care. 2012 Oct 15.

13. Gallagher H, Cooper M, Durand C. Effects of an Interdisciplinary Volunteer Experience on Students' Knowledge of and Attitudes Toward the Health Care Team. Journal of Physician Assistant Education. 2010; 21(3): 27-30.

14. Galt KA, Paschal KA, O'Brien RL, McQuillan RJ, Graves JK, Harris B, et al. Description and Evaluation of an Interprofessional Patient Safety Course for Health Professions and Related Sciences Students. Journal of Patient Safety. 2006;2(4):207-16. 
Ross,E, Derouin,A, Halstater, B, Covington, K, Kaprielian, V, Murphy, G, Dieter,P

15. Hall P, Weaver L. Interdisciplinary education and teamwork: a long and winding road. Med Educ. [Research Support, Non-U.S. Gov'tReview]. 2001 Sep;35(9):867-75.

16. McCallin A. Interdisciplinary practice--a matter of teamwork: an integrated literature review. J Clin Nurs. [Review]. 2001 Jul;10(4):419-28.

17. Horsburgh M, Merry AF, Seddon M. Patient safety in an interprofessional learning environment. Med Educ. 2005 May;39(5):512-3.

18. Erb D, Kaprielian V, Dieter P, Nevidjon B, Eldredge B, McNamara R. Improving Interprofessional Understanding via Interprofessional Case Conferences. MedEdPORTAL; 2011. Available from: www.mededportal.org/publication/8437 
TABLE 1

Process of ICC Case Development

\begin{tabular}{|c|c|}
\hline \multicolumn{2}{|r|}{ Over 2-3 months } \\
\hline Step 1 & ICC Leadership Team develops the learning objectives for the case \\
\hline Step 2 & $\begin{array}{l}\text { One or two members of the ICC Leadership Team develops the patient case including: } \\
\text { - Medical, reproductive, and surgical histories } \\
\text { - Current and past medications } \\
\text { - } \text { - Social history, including occupational and environmental exposures } \\
\text { - Employment history } \\
\text { - Family history } \\
\text { - Comprehensive review of systems } \\
\text { - Detailed physical examination } \\
\quad \text { Including specialized examinations (examples included physical } \\
\text { therapy examinations unique to this field that others at the ICC could } \\
\text { learn from) }\end{array}$ \\
\hline Step 3 & $\begin{array}{l}\text { ICC Leadership Team reviews and edits developed case to ensure educational and } \\
\text { clinical appropriateness }\end{array}$ \\
\hline Step 4 & Case authors review edits, make changes, and resubmit to ICC Leadership Team \\
\hline Step 5 & Steps 3 and 4 repeat as often as needed to refine case \\
\hline Step 6 & $\begin{array}{l}\text { ICC Leadership Team approves case in final format, to be used as the Standardized } \\
\text { Patient training materials }\end{array}$ \\
\hline Step 7 & $\begin{array}{l}\text { Case authors edit case to a smaller document that becomes the "Facilitator's Guide" } \\
\text { with specific instructions, to be used by the ICC facilitators }\end{array}$ \\
\hline
\end{tabular}


TABLE 2

ICC Case Primary Diagnoses and Utilization Frequency

\begin{tabular}{lc}
\hline \multicolumn{1}{c}{ ICC Case } & $\begin{array}{c}\text { Number of Times } \\
\text { Used }\end{array}$ \\
\hline Pneumonia & 2 \\
Carpal Tunnel, Anxiety & 2 \\
Alcohol Abuse, MVA & 2 \\
Low Back Pain & 2 \\
Vertigo & 1 \\
Diabetic Ulcer, Erectile Dysfunction & 1 \\
Urinary Incontinence & 1 \\
Stroke, Knee Pain & 1 \\
Heart Palpitations & 1 \\
Bulimia & 1 \\
Shoulder Pain & 1 \\
Headache & 1 \\
Concussion & 1 \\
\hline
\end{tabular}


Table 3

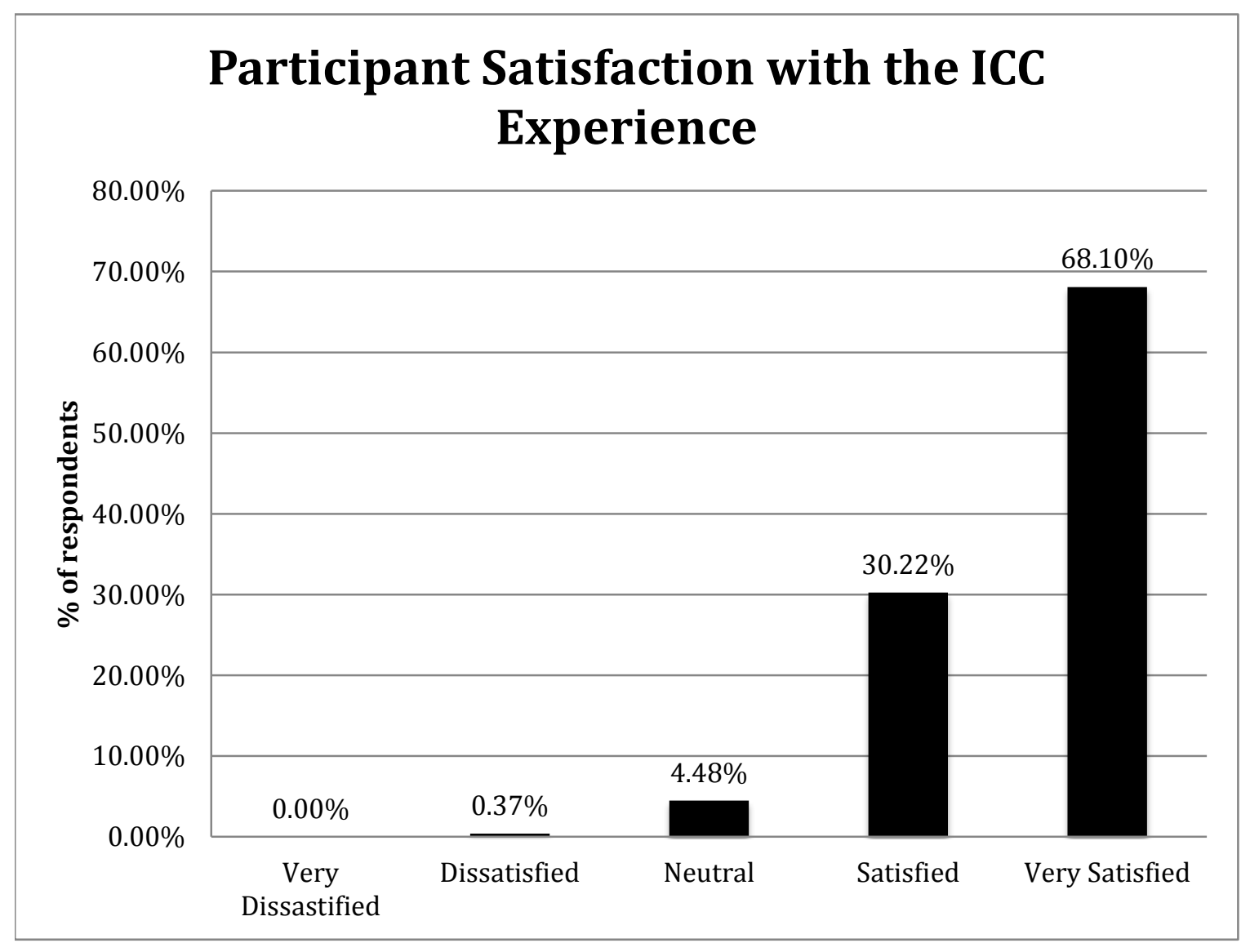


Table 4

ICC Participant Feedback - Representative Comments from Surveys

What was the most important thing you learned?

- "I enjoyed the interaction with colleagues from other disciplines. It was great to hear other interviewing styles"

- "The benefit of the teamwork and collaboration and how it impacted the interview and treatment plan"

- "Watching other practices interview the patient was helpful as far as seeing what other professions are asking \& thinking when approaching patients"

What remains unclear?

- "The best way to coordinate between multiple providers"

- "Putting it all together. Great as far as perspectives having us all together in practice seems like another hurdle all together"

How could we improve this experience?

- "I can't think of anything except having these conferences more often."

- "Have the 'patient' provide constructive criticism to students about their communication styles"

- "It might be interesting for different team members to have different information, and to have to share that information"

- "Have an equal balance of professions represented in the team"

- "There were nine students in my group. This was too many students. It might be helpful to have smaller groups."

- "More professional disciplines should be included." 


\section{APPENDIX 1}

\section{Facilitator Guide \\ Patient: Kevin Green}

All times are approximate. Please manage discussion as you need to in order to complete the tasks by 7:10. Students need to be in room 208 at 7:15.

\section{5:30 Introductions}

- Go around the room and have everyone introduce themselves - name, program, why they chose to participate in this program or what they hope to learn this evening

- Outline the plan for the evening:

- Group discussion of the case

- Interview with standardized patient

- Group problem-solving to develop a plan

- Discussion of the plan with the patient

- Debriefing

- Emphasize to the group that this exercise is not evaluated in any way. It is a multidisciplinary case conference. The goal is to work as a team and communicate effectively with other disciplines. No one's performance is being evaluated.

- Emphasize safety and confidentiality in the learning environment.

- If students arrive late, allow a moment for them to introduce themselves (name and program), and proceed as you were.

\section{5:40 Case presentation}

- Read the following case intro to the students: You are seeing patients in a primary care outpatient practice. Mr. Green is a 55 year old man who is concerned about a sore on his foot that is not healing.

- Have the students read the instructions on their handout:

Within your multidisciplinary group, you are to formulate questions to ask the patient that will determine your plan of care. You do not need to physically examine the patient, only talk with him or her. For example, some of the things to consider for this patient are:

1. What medical history is relevant for this issue?

2. What other issues might we need to think about?

Facilitate group discussion as the students decide information they want to gather from the patient.

- Have the students decide who will interview the patient first. Encourage multiple students to take the opportunity to play the clinician role. Remind the students that this is a good chance to practice patient interaction skills.

- Check that all students understand the procedures for standardized patients.

- Discuss the process for "time out." Remind students that if the interviewer ever feels "stuck," they can call a time out and ask the group for help.

- Arrange chairs for the interview so that the patient and clinician are seated near each other in a realistic fashion. Have each student that plays the clinician move into the clinician chair before interacting with the patient.

- Remind the students that the objective is not to grill the patient, but to get information. Encourage use of open ended questions. They have reminders of open-ended questions on their handouts. 


\section{5:55 Standardized Patient Interview}

- Invite the patient into the room and escort the patient to the patient chair.

- Students will interview the patient one at a time, as you have planned as a group.

- Use time out as needed. Because of time limitations, try to keep these short.

- Excuse the patient from the room when the students are satisfied that they have sufficient historical information to determine a care plan.

\section{6:15 Physical Exam}

- Ask the students what physical exam they would perform.

- Provide them with the results for only those parts of the exam they request.

○ Vital signs: T: 98 P: 72 R: 16 BP: 130/82 L arm

- Head: Scalp without lesions, normocephalic/ atraumatic.

- Eyes: Vision 20/25 each eye with handheld Snellen chart (with reading glasses). Visual fields full by confrontation. Conjunctiva pink; sclera white. Pupils equal and round, reactive to light. Disc margins sharp, without hemorrhages, exudates. No arteriolar narrowing or A-V nicking. No neovascularization.

- Ears: Canals clear and TMs demonstrate normal landmarks. Acuity good to whispered voice. Weber midline. Rinne: $\mathrm{AC}>\mathrm{BC}$, both ears.

- Chest/Lung exam: normal.

- Cardiac: Regular rate and rhythm, normal S1, S2, with no murmur or gallop

- Musculoskeletal: Grossly intact. Detailed exam not done. No deformity. Moves normally.

- Extremities: No clubbing, cyanosis, or edema. Feet with some calluses, cracking on heels. Nails properly trimmed. Skin intact except nickel-sized ulcer under 2nd metatarsal head of the right foot, with some adherent eschar. No pus or odor but some minimal drainage.

- Neurologic:

- Cranial nerves 2-12 intact to testing. No nystagmus.

- Sensation normal to light touch and pinprick over arms

- Feet with decreased sensation to vibration, light touch and pinprick in both feet, right greater than left. Sensation using a Semmes-Weinstein 5.07 (10 g) monofilament is intact at 2 out of 6 locations on the right plantar and dorsal surfaces, and 4 out of 6 on the left.

- Muscle strength was normal and symmetric in the upper and lower extremities.

- DTRs were normal and symmetrical.

- Clinical tests of cerebellar function (finger to nose, rapid alternating movements) normal. Heel/toe walking normal, except right toe walking which elicits 1/10 pain.

- Negative Hoffmann's, Babinski; no clonus. 


\section{6:25 Care planning}

- Facilitate the group as they discuss their impressions and formulate an interdisciplinary care plan.

- Encourage the students to draw on each others' knowledge and experiences. Give information/guidance when necessary to enable the group to progress, but avoid playing the expert.

- Consider having someone serve as scribe to record the plan on a whiteboard or flipchart. Evaluation and management plans for the patient should consider:

- Pharmacologic therapy

- Non-pharmacologic therapy

- Role of team in management

- Indications for follow up, indications for more aggressive intervention

- Resources for assistance

- Explain to the students that they are now to communicate their recommendations to the patient. Determine how they would like to approach the discussion, who will start the interview, and succeeding interviewers as desired. Encourage students to check should be encouraged to check in with the patient while giving the feedback to make sure he understands what they are saying, and to discover possible barriers to compliance.

\section{6:40 Patient counseling}

- Invite the patient back into the room.

- Students will speak with the patient one at a time, as you have planned as a group.

- Use time out as needed. Ensure that the care plan discussion is patient-centered.

\section{7:00 Debrief}

- Break out of roles.

- If you reach this point ahead of schedule, you may wish to debrief the interviews.

- Thank the SP for their efforts, and excuse them.

- Invite the group to discuss their functioning as a team.

- What did they do that was successful?

- How might they do it better in the future?

- Were there discipline-specific issues of language or behavior that affected collaboration?

\section{7:10 Adjourn small group}

- Thank the group for their participation.

- Walk students to the large group room 208 for final discussion (and prize drawing!).

- Remind them to fill out their evaluation forms.

\section{7:15 Conclude meeting [in large group]}

- Key points of case are reviewed

- Wound management

- Diabetic foot care

- Medications for prevention

- Consider low-dose ACEI (lisinopril, etc) for prevention of nephropathy

- Consider low-dose statin for prevention of CVD

$\circ$ ED management

- PDE5 inhibitors (Viagra, Cialis, Levitra)

- Maintenance of functional and fitness levels

- Evaluations collected

- Prize drawing takes place 
APPENDIX 2

Name

Education Program

\section{Interprofessional Case Conference}

Evaluation

What was the most important thing you learned from this experience?

What remains unclear?

How could we improve this experience?

Suggestions for future topics?

Would you be interested in participating in something like this again?

What other comments do you have?

Please rate your overall experience. Circle one:

$\begin{array}{ccccc}\text { Very dissatisfied } & \text { Dissatisfied } & \text { Neutral } & \text { Satisfied } & \text { Very Satisfied } \\ 1 & 2 & 3 & 4 & 5\end{array}$

